\title{
O ASSOCIATIVISMO COMO ESTRATÉGIA DE ESCOAR A PRODUÇÃO DA AGRICULTURA FAMILIAR DO MUNICÍPIO DE ABAETETUBA-PA
}

\author{
Leonardo Figueiredo de Souza ${ }^{1}$ \\ Julia Hassegawa Moura ${ }^{2}$ \\ Carla Lorena Sandim da Rosa ${ }^{3}$ \\ Ana Júlia Mourão Salheb do Amaral ${ }^{4}$ \\ Aquiles Simões ${ }^{5}$
}

O município de Abaetetuba fica no interior do estado do Pará, localizada na Região do Baixo Tocantins. A cidade acompanha as margens do rio Maratauíra, como seguiu seu crescimento urbano. O município é o $2^{\circ}$ maior produtor de açaí (Mercado Físico Rural 2019) e é conhecido como Capital Mundial do Brinquedo de Miriti, fruto de uma palmeira da região de várzea. Contém aproximadamente 72 ilhas e é dividida em dois distritos, a cidade de Abaetetuba (sede) e a Vila de Beja, região onde muitos produtores fazem morada em ramais e assentamentos na beira da estrada.

$\mathrm{Na}$ Cidade de Abaetetuba, foi planejada a Associação dos Agricultores Familiares de Abaetetuba (AFAFA), pela prefeitura e pela EMATER (Instituto Paraense de Assistência Técnica e Extensão Rural) convidando agricultores para a construção do espaço na sede da EMATER (FADECAM 2019). A Feira acontece toda sexta e sábado, das $8 \mathrm{~h}$ às $12 \mathrm{~h}$ e conta com cerca de 72 produtores. Nela, são vendidos diversos produtos regionais como os derivados da mandioca, frutas e hortaliças da região, plantas ornamentais e medicinais, vasos de cerâmica, licores e doces com frutos regionais.

A Feira da AFAFA oferece aos produtores participantes a movimentação da sua mercadoria de forma autônoma, com relação ao preço, quantidade e tipos de produtos oferecidos. Além disso, o contato do produtor com os consumidores do resultado do seu trabalho favorece e incentiva a produção pelo retorno quanto a qualidade do que foi

\footnotetext{
${ }^{1}$ Universidade Federal do Pará, Brasil. Email: leof.amazonia@gmail.com ORCID ID: https://orcid.org/0000-0001-8789-127X

${ }^{2}$ Universidade Federal do Pará, Brasil. Email: juliahassegawa3@gmail.com ORCID ID: https://orcid.org/0000-0002-0530-0817

${ }^{3}$ Universidade Federal do Pará, Brasil. Email: lorena.sandim@hotmail.com ORCID ID: https://orcid.org/0000-0002-5550-9571

${ }^{4}$ Universidade Federal do Rio Grande do Sul, Brasil. Email: anaagro4@gmail.com ORCID ID: https://orcid.org/0000-0003-2321-0177

${ }^{5}$ Universidade Federal do Pará, Brasil. Email: moinayunah@gmail.com ORCID ID: https://orcid.org/0000-0003-2194-6594
} 
consumido. Essa troca de experiência dos circuitos curtos de comercialização se afasta da supervalorização do capital e do prático, fortalecendo os saberes dos povos tradicionais cultivados na Agroecologia para enfrentar o desastre socioambiental do processo civilizatório (Caporal et al, 2011).

O Associativismo para esses (as) agricultores (as) familiares (as) surgiu como uma alternativa de escoar o que produzem, através da rede de circuitos curtos de comercialização (como já fora mencionado) que além de proporcionar uma relação entre produtor e consumidor, se constrói através de um empreendimento coletivo e solidário.

Em sua maioria, os agricultores conheceram o trabalho no campo com os pais ainda na infância e passaram a produzir a partir dos conhecimentos repassados. Assim, a produção é orgânica como aprenderam de forma tradicional e "natural" como relataram muitos agricultores nas entrevistas da pesquisa ${ }^{6}$ que fizemos em visita à feira que também resultou neste registro fotográfico.

\section{REFERÊNCIAS}

MERCADO FÍSICO RURAL. Disponível em:

https://www.mfrural.com.br/mobile/cidade/abaetetuba-pa.aspx. Acesso em: 7 janeiro 2020 .

UNIVERSIDADE FEDERAL DO PARÁ FADECAM FACULDADE DE FORMAÇÃO E DESENVOLVIMENTO DO CAMPO. Disponível em: https://fadecam.ufpa.br/index.pcamhp/notícias/item/31-associacao-dos-agricultoresfamiliares-de-abaetetuba-obtem-selo-nacional. Acesso em: 7 janeiro 2020.

CAPORAL, F. R. et al. Princípios e perspectivas da agroecologia. Instituto Federal de educação, ciência e tecnologia do Paraná e educação a distância. p. 46, 2011.

Recebido: $08 / 04 / 2020$

Aprovado: $08 / 12 / 2020$

\footnotetext{
${ }^{6}$ Desenvolvida no âmbito do NEA GEDAF: Teias de Inovação Agroecológica e Desenvolvimento de Sistemas Agroalimentares com o apoio do Conselho Nacional de Desenvolvimento Científico e Tecnológico - CNPq e dos órgãos financiadores da Chamada CNPq 21/2016, a saber: MAPA, MCTIC, MEC e SEAD - Casa Civil.
} 


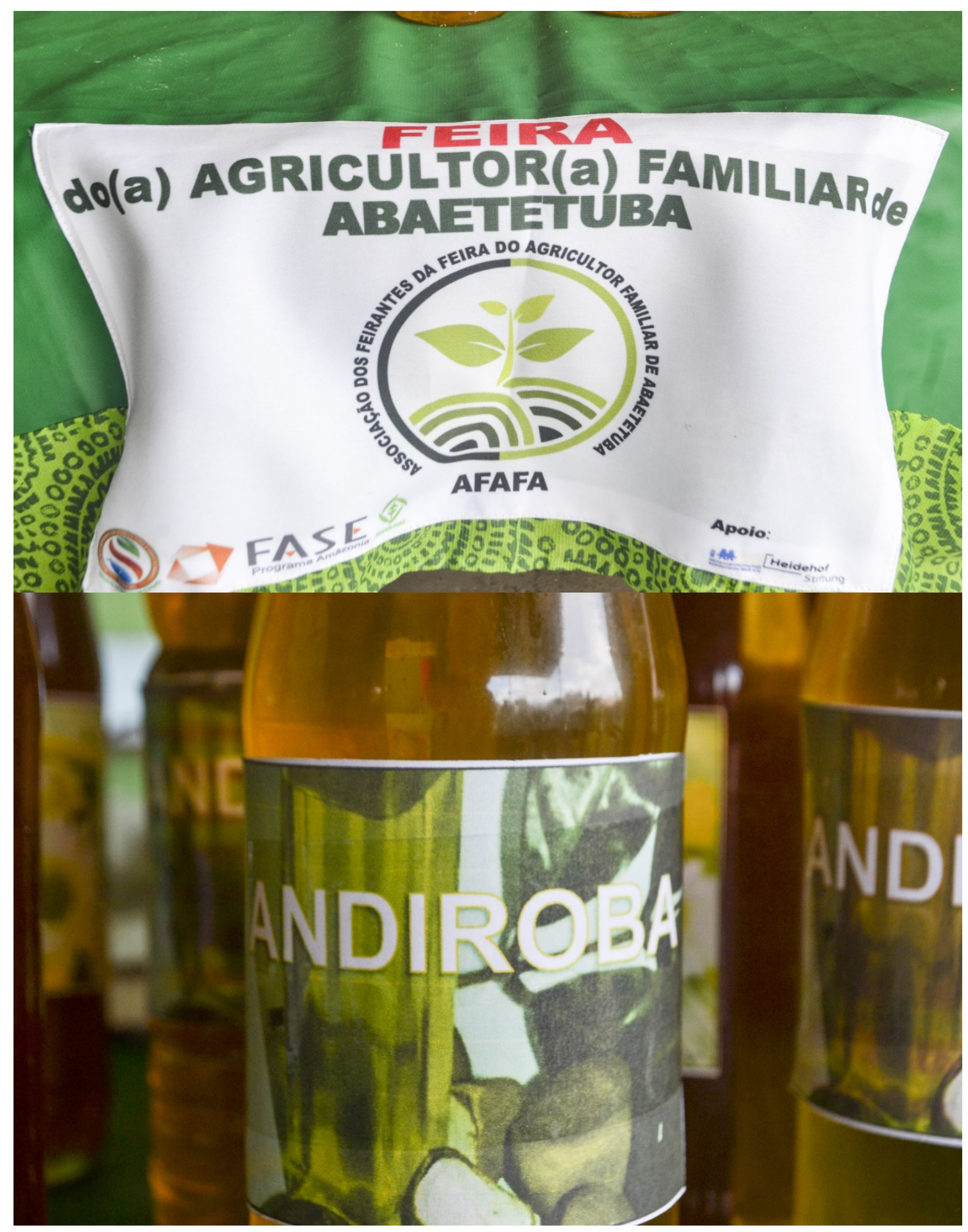




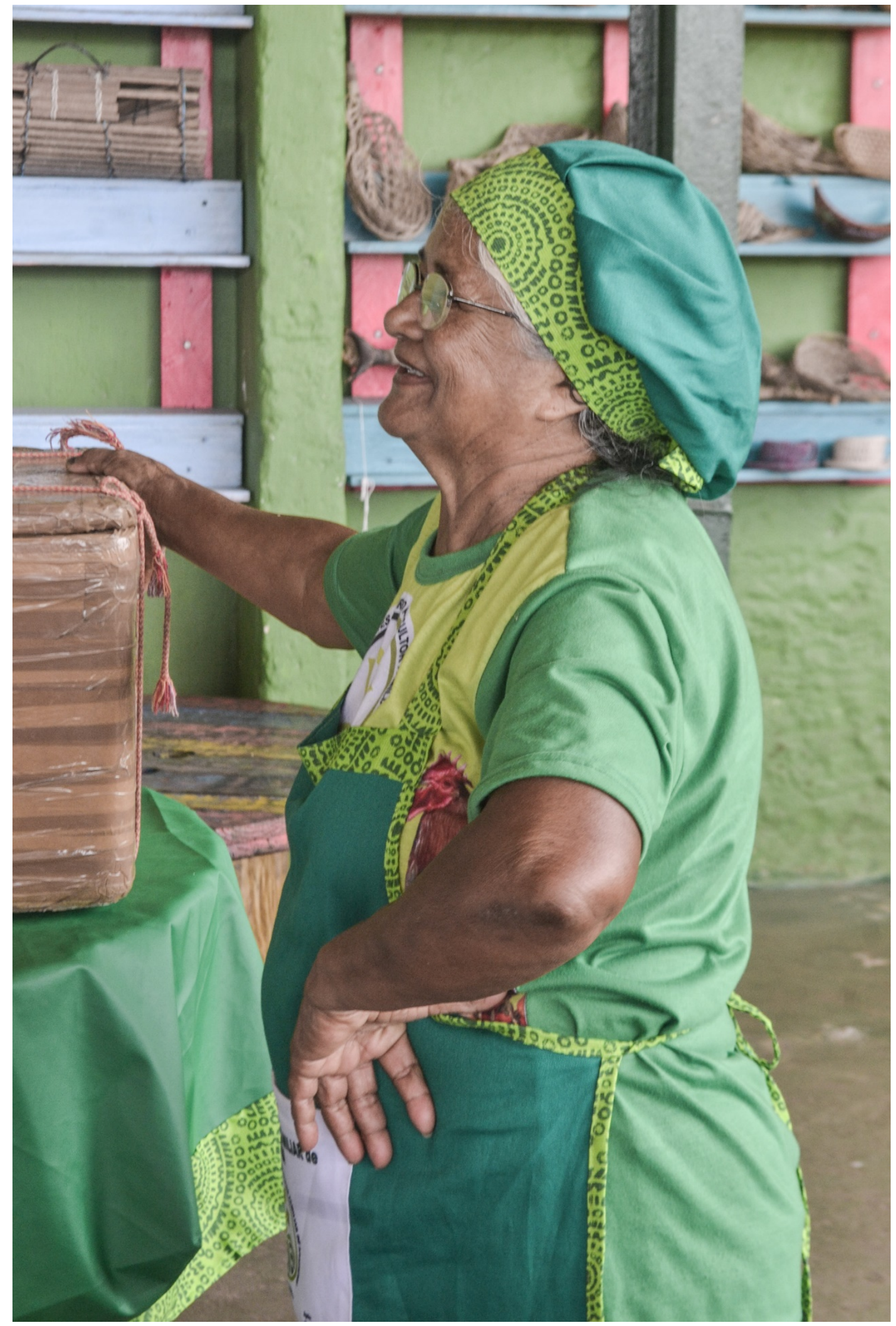




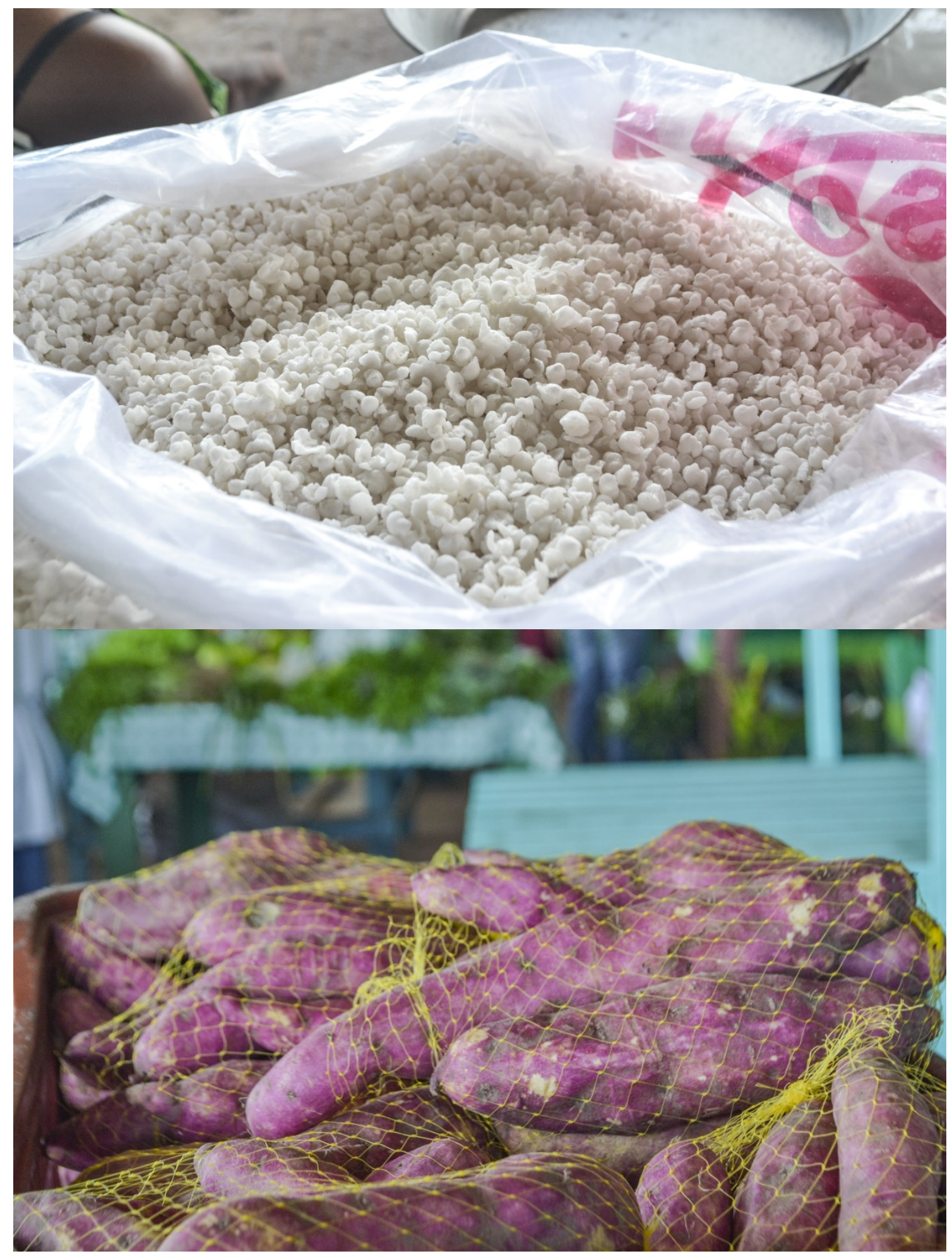




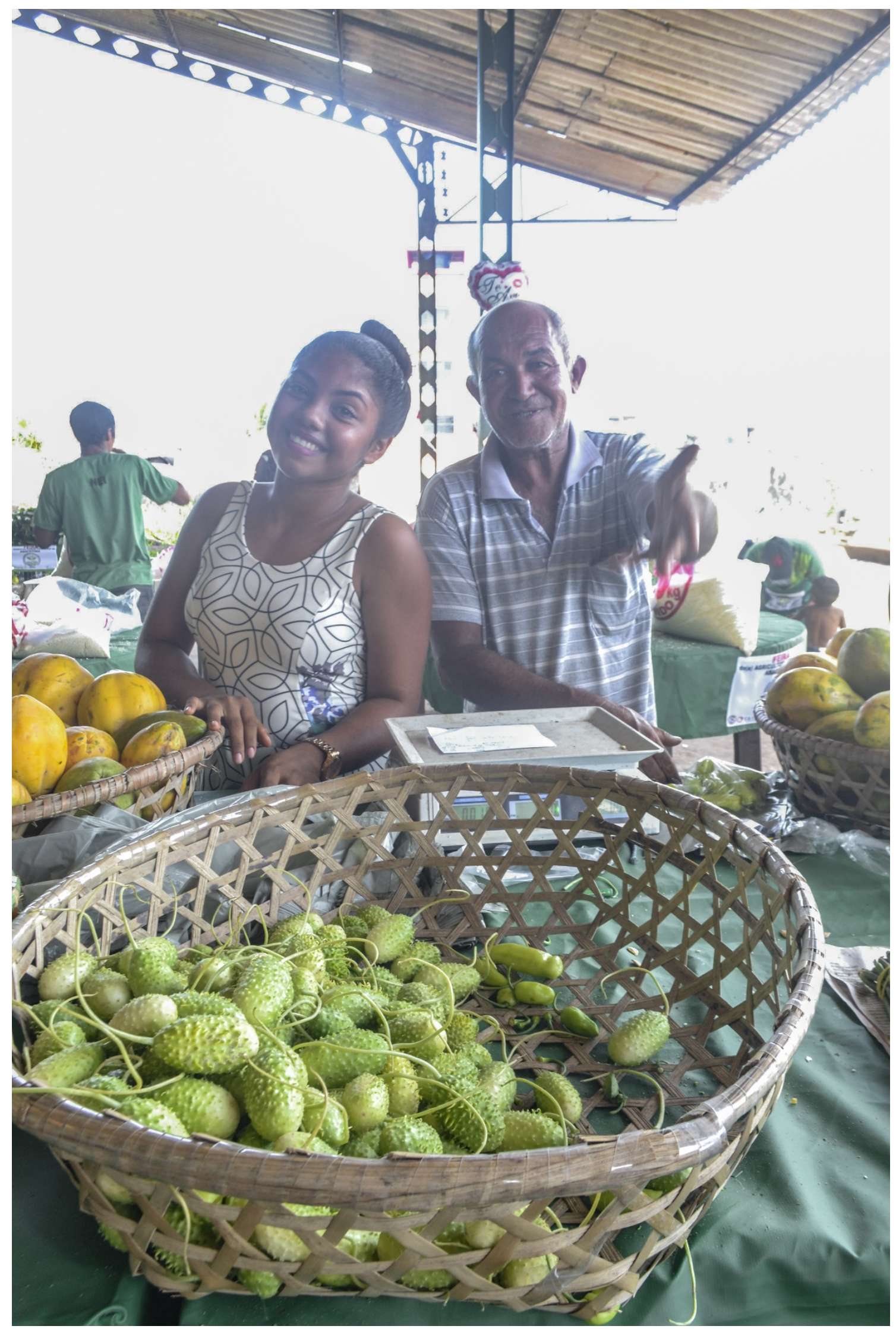




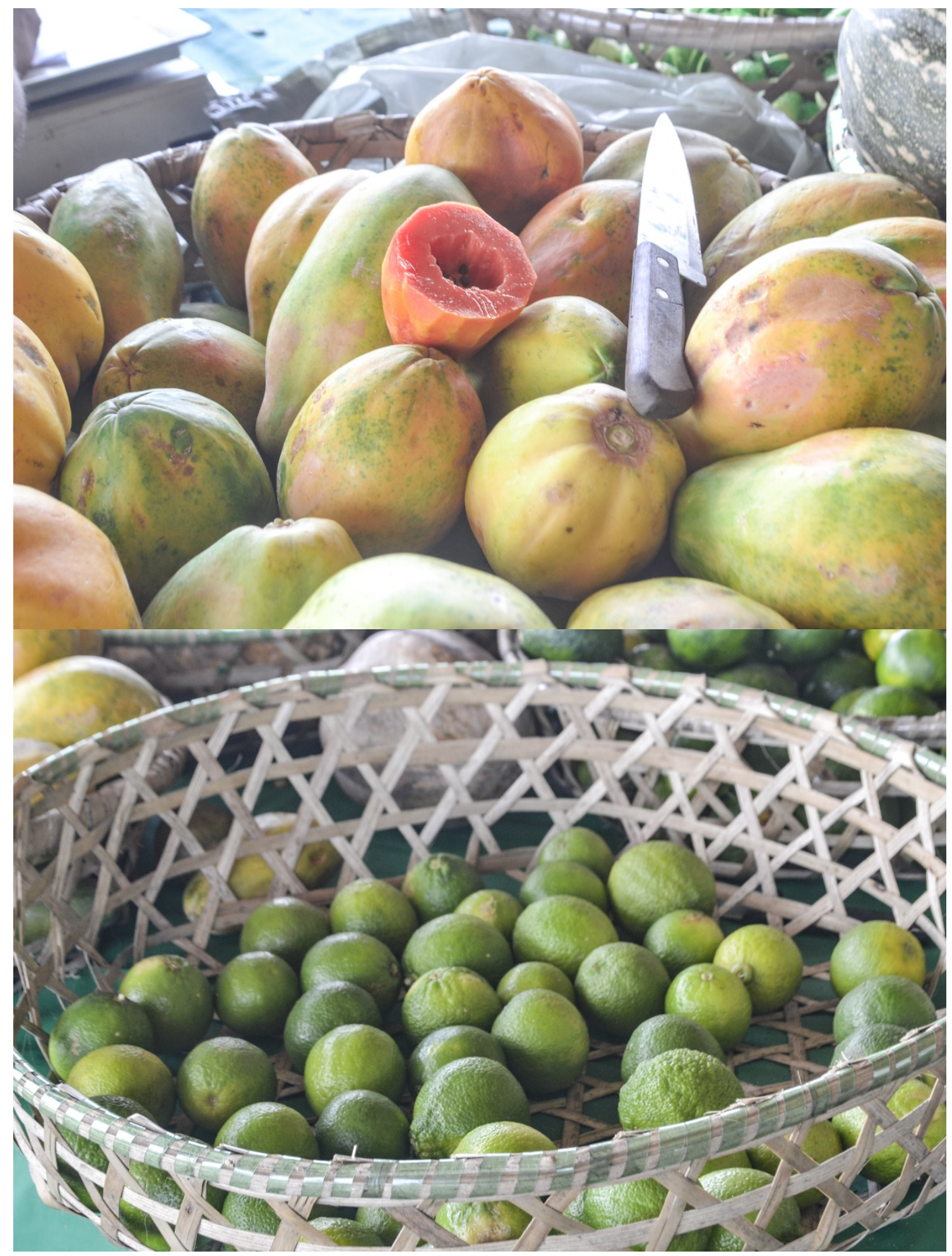




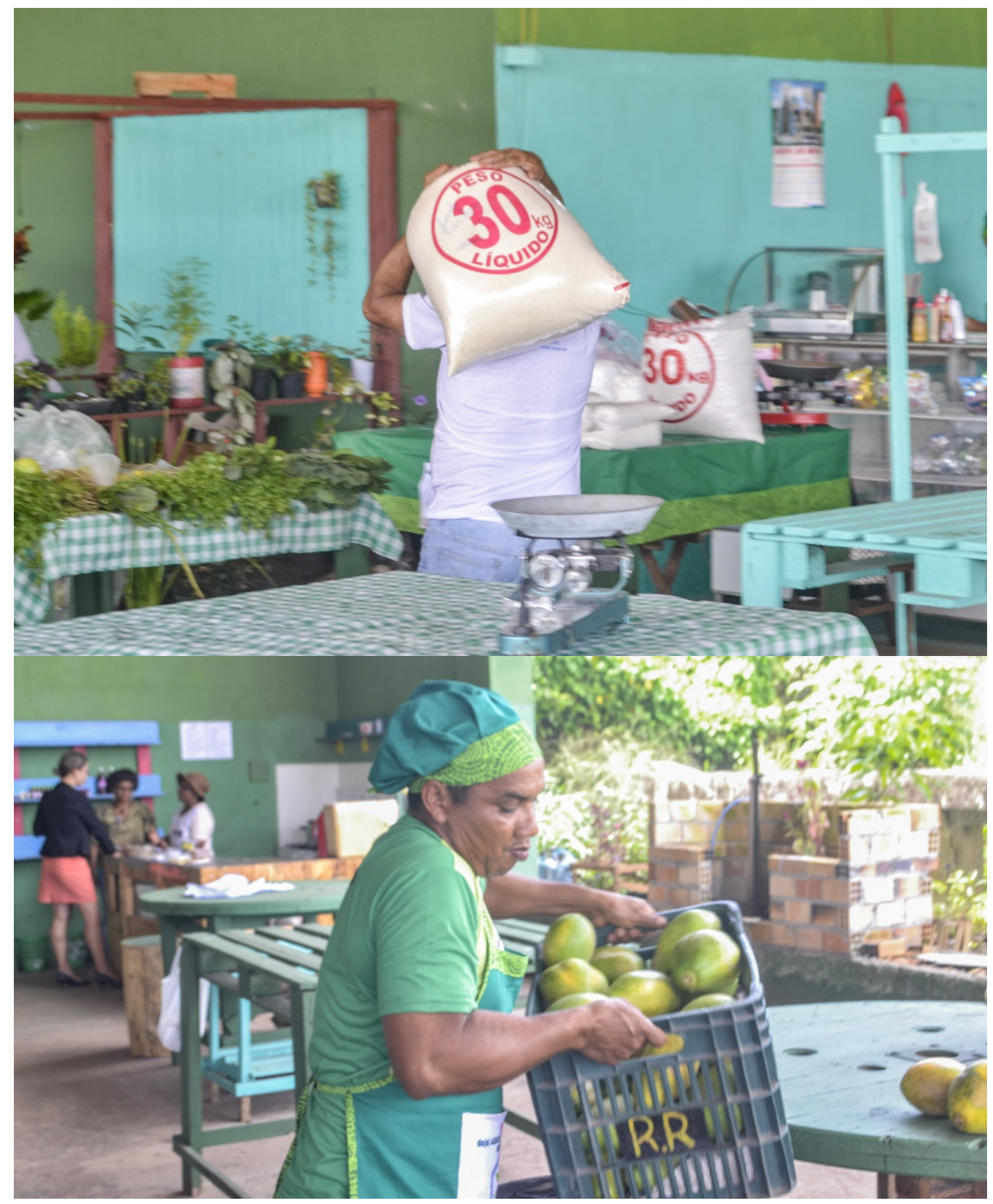



Município de Abaetetuba-PA

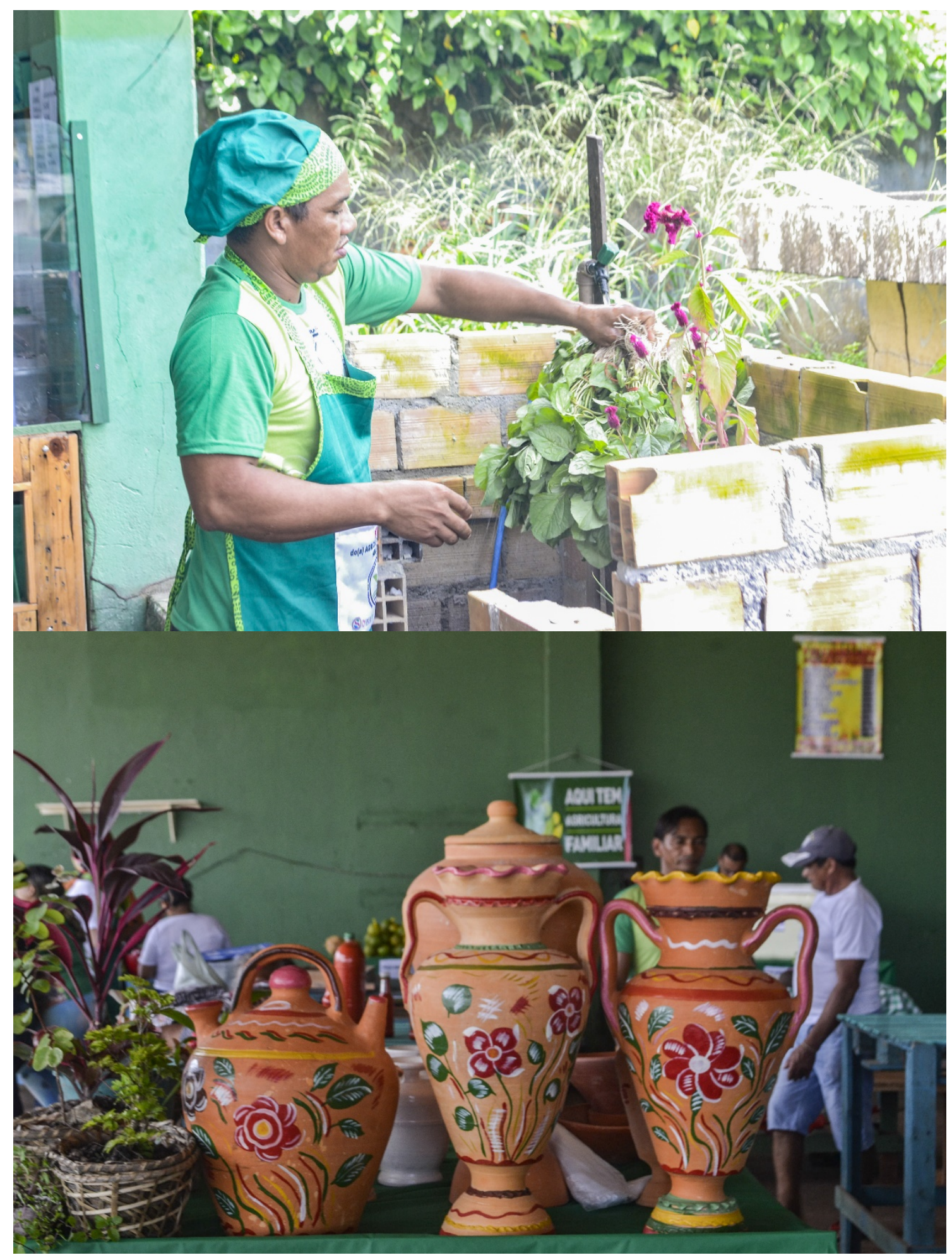









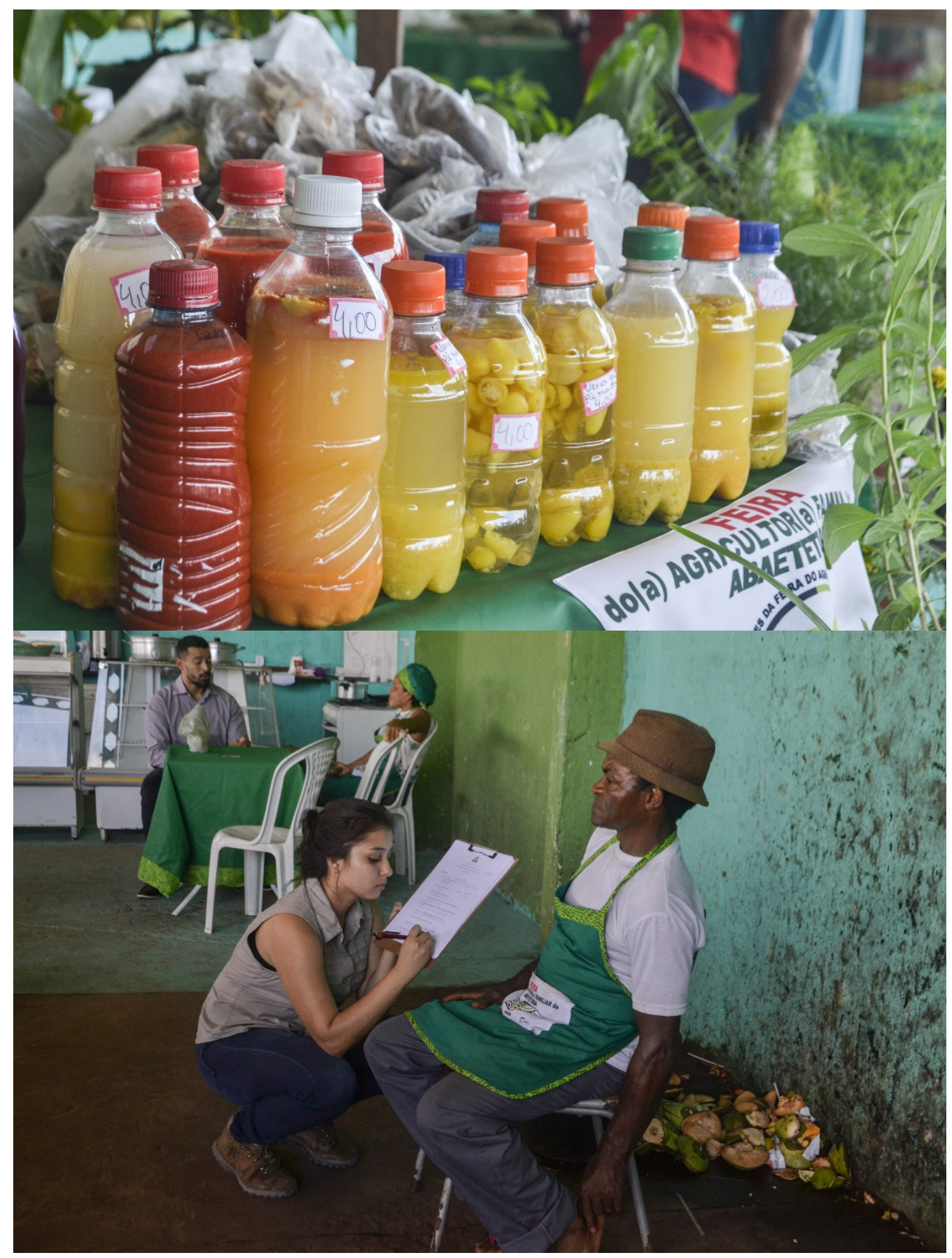



Júlia Mourão Salheb do Amaral \& Aquiles Vasconcelos Simões

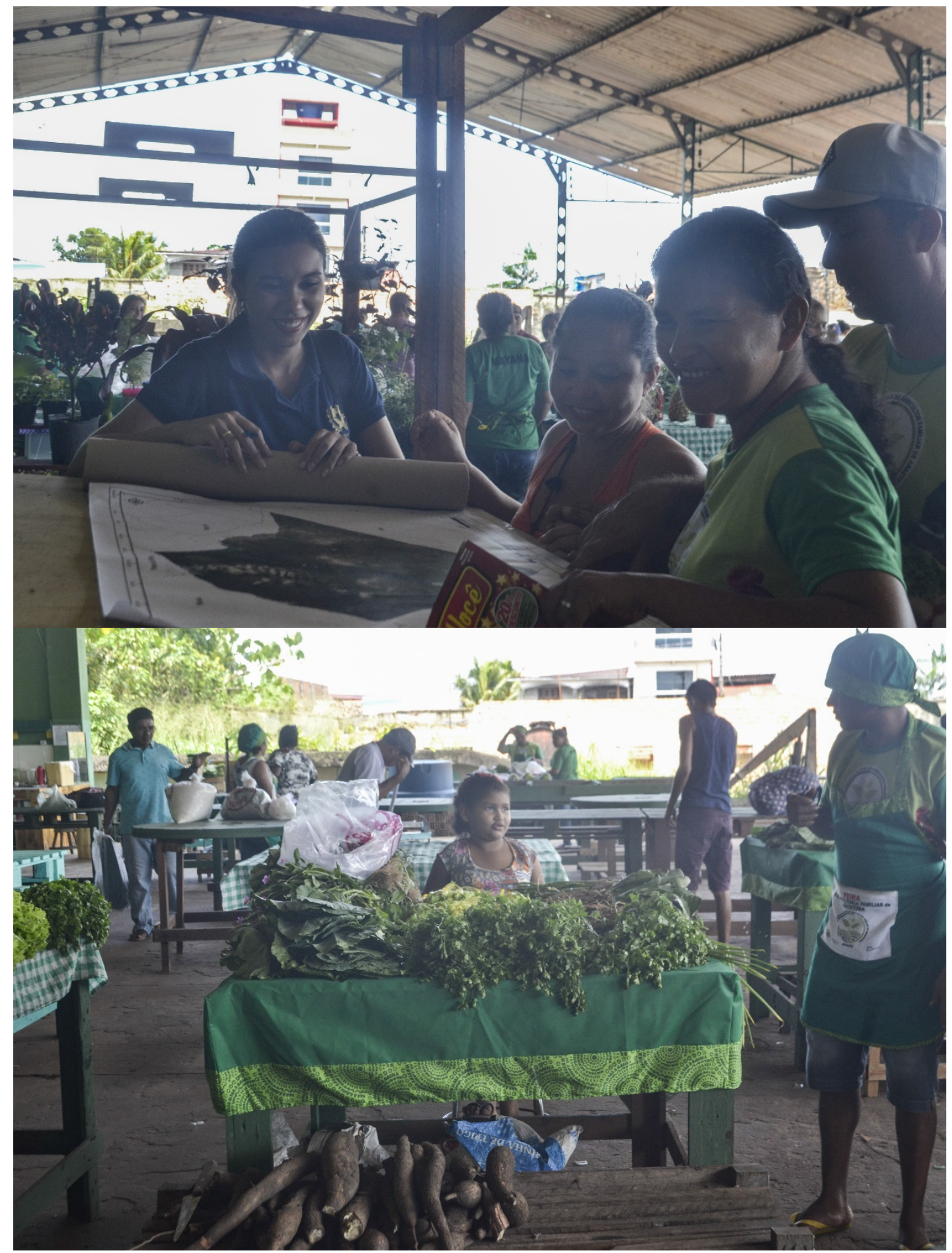




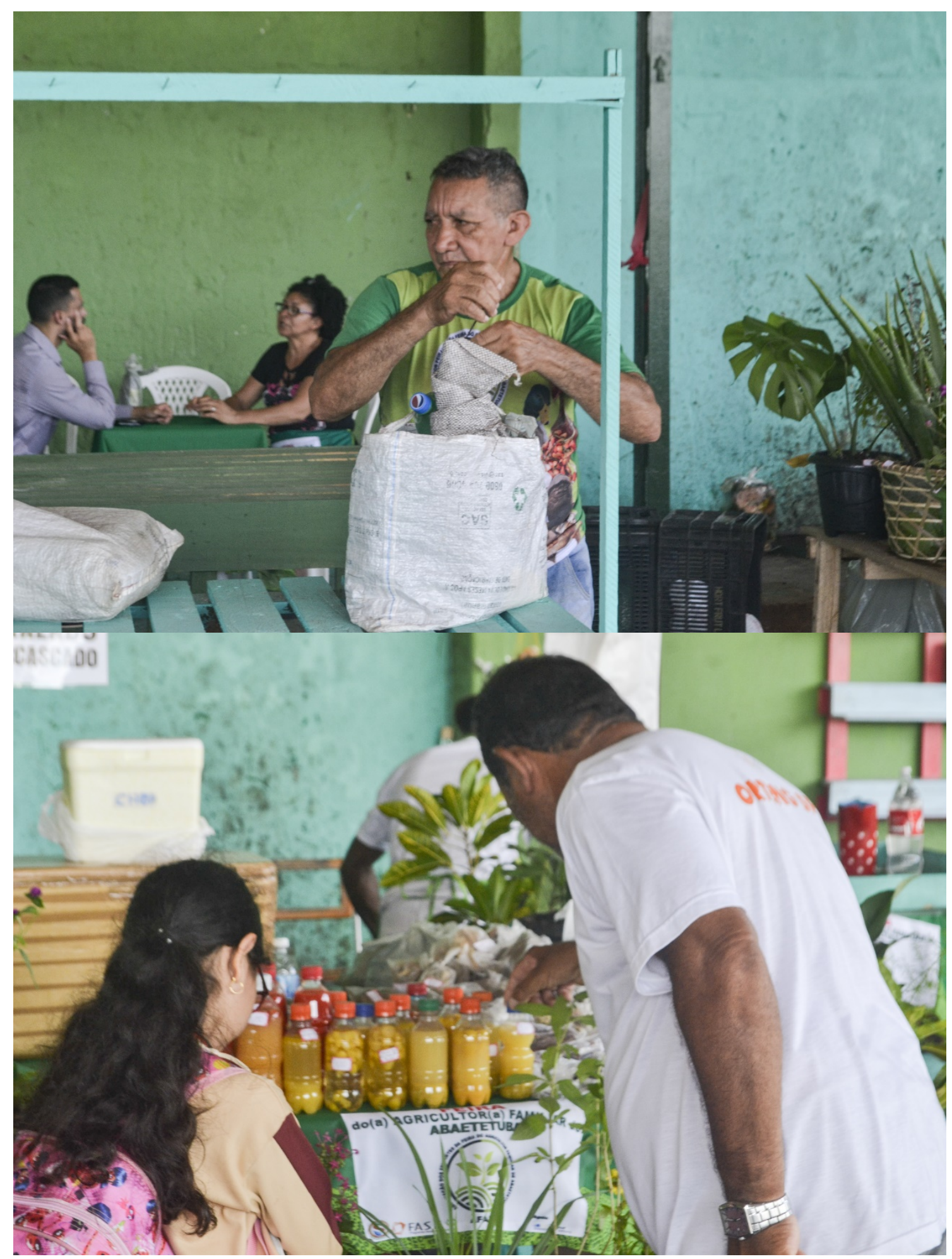




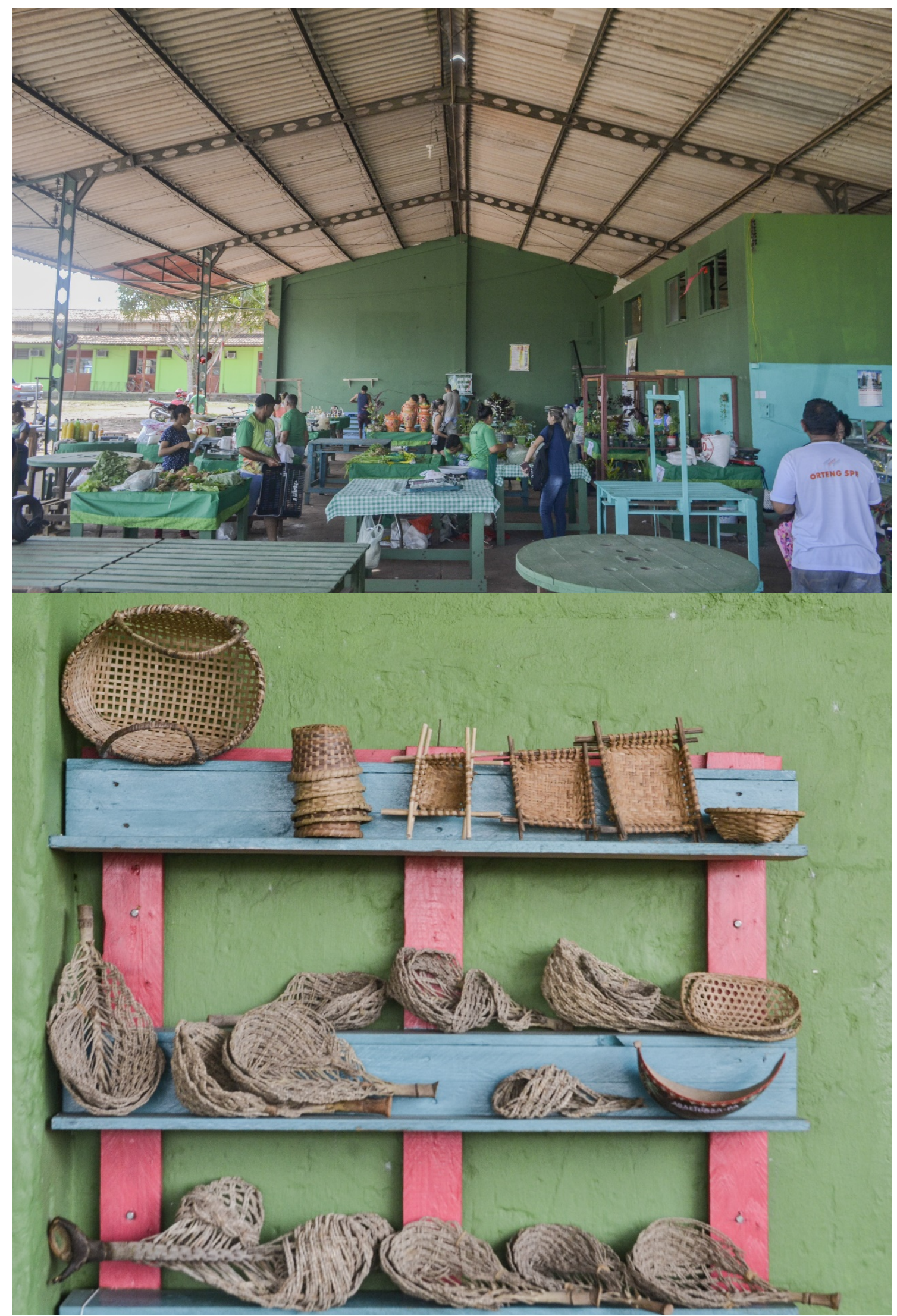




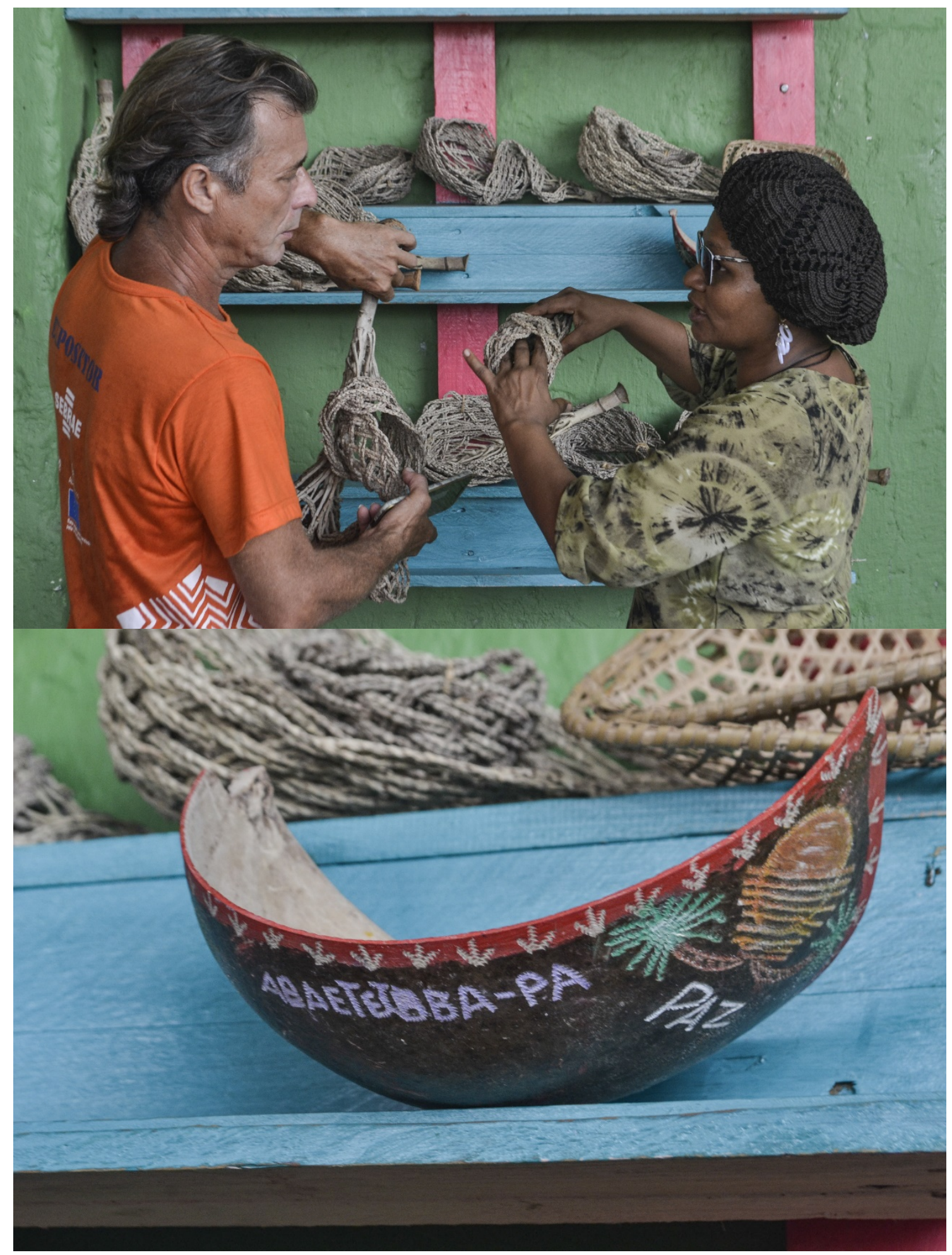




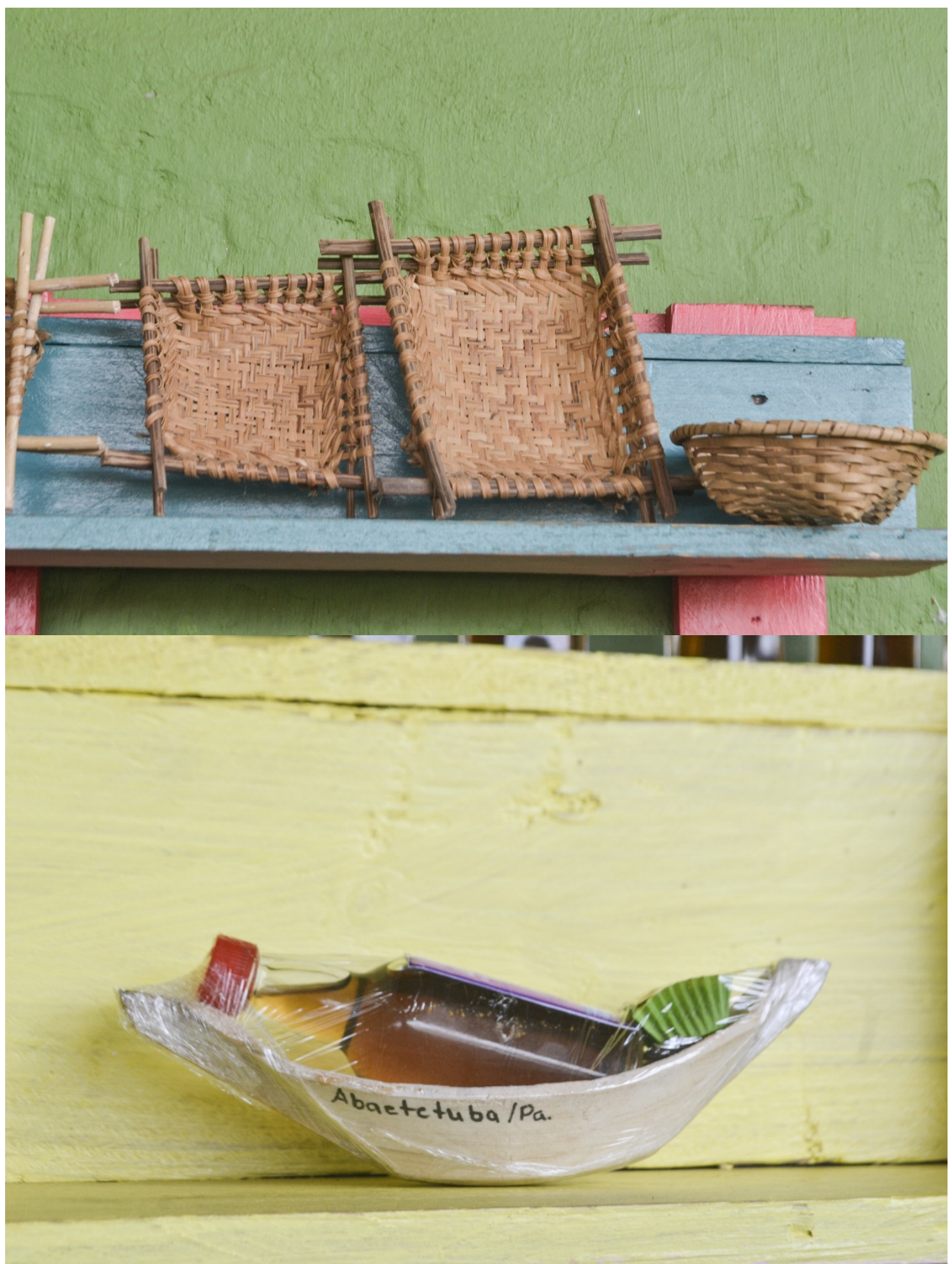




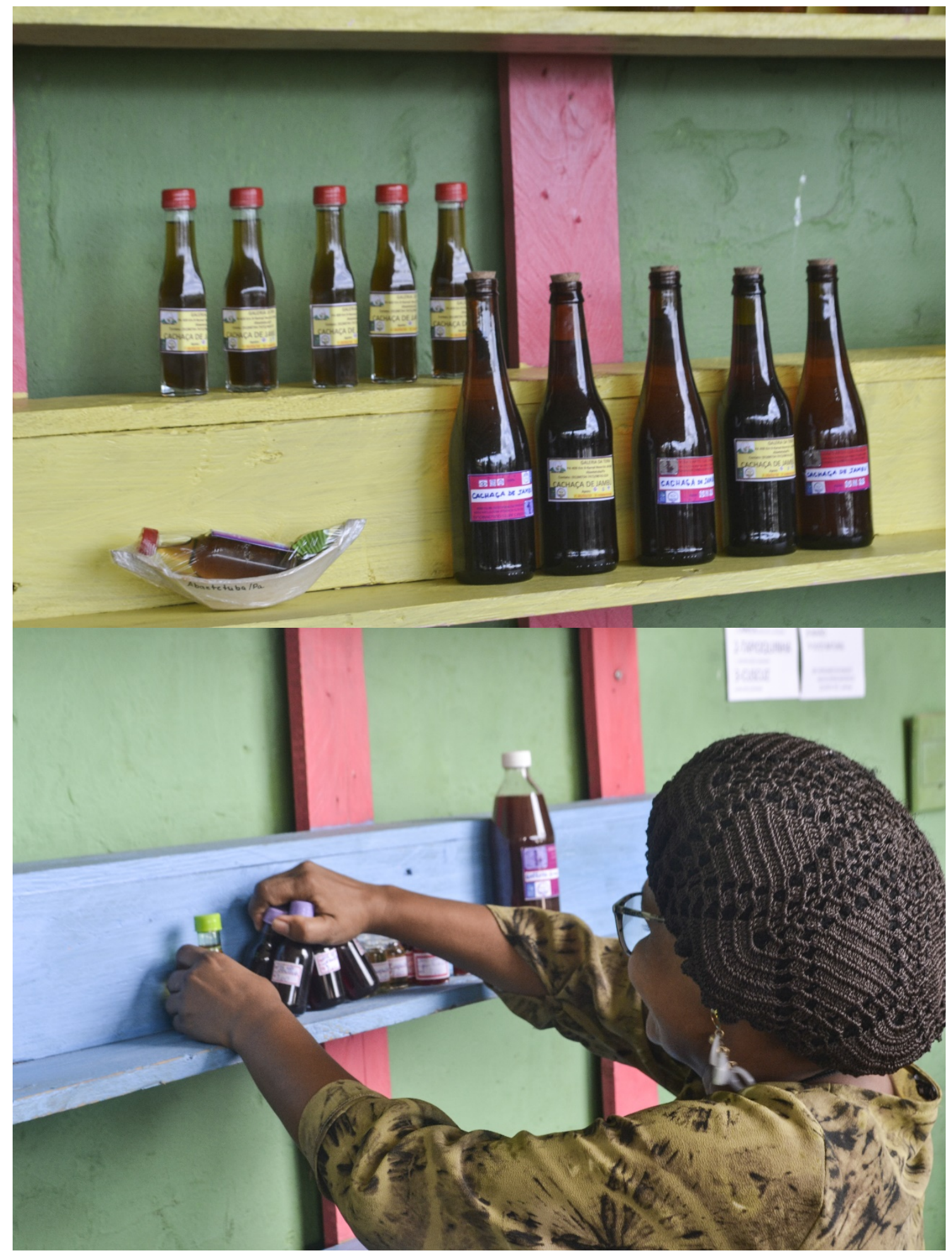




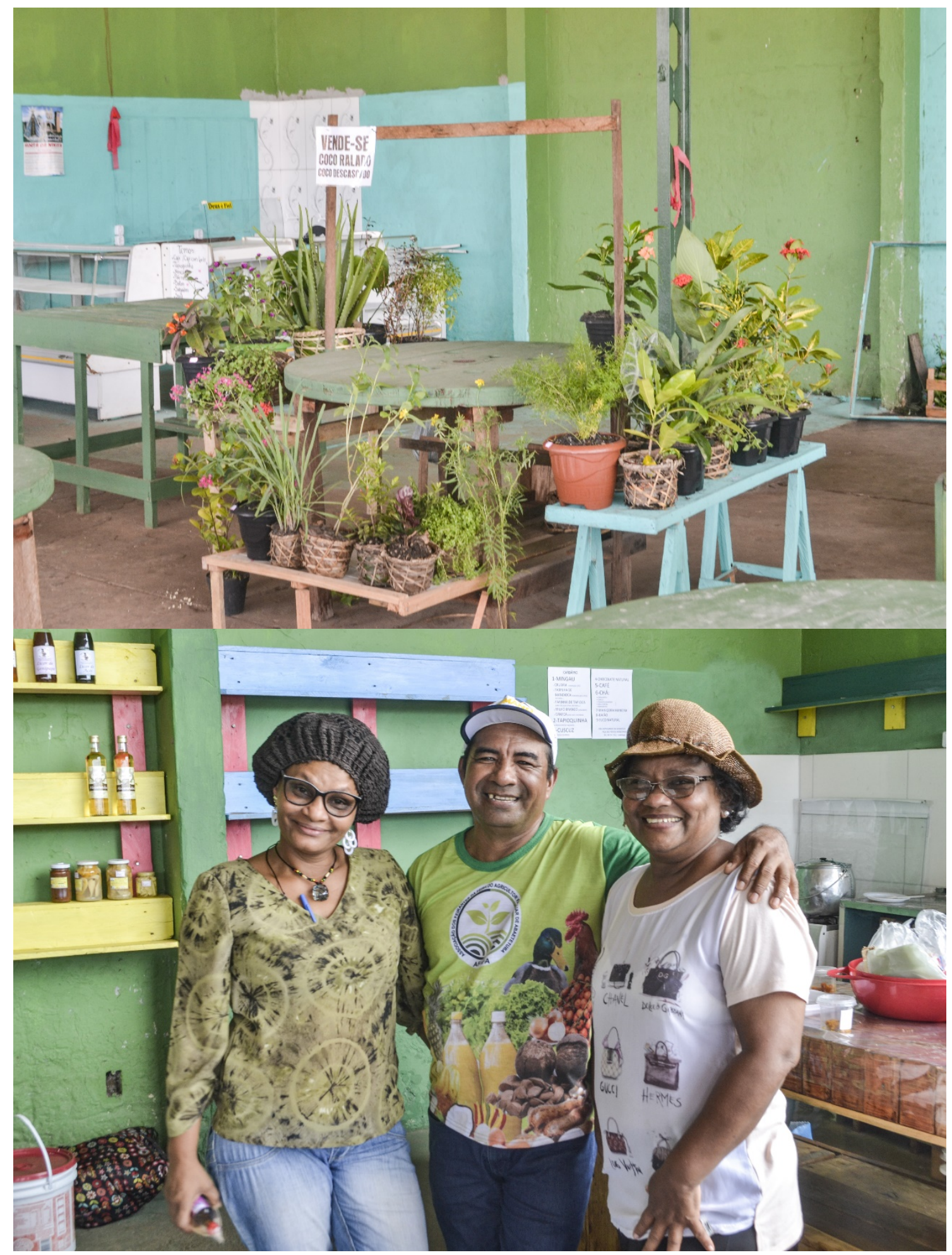



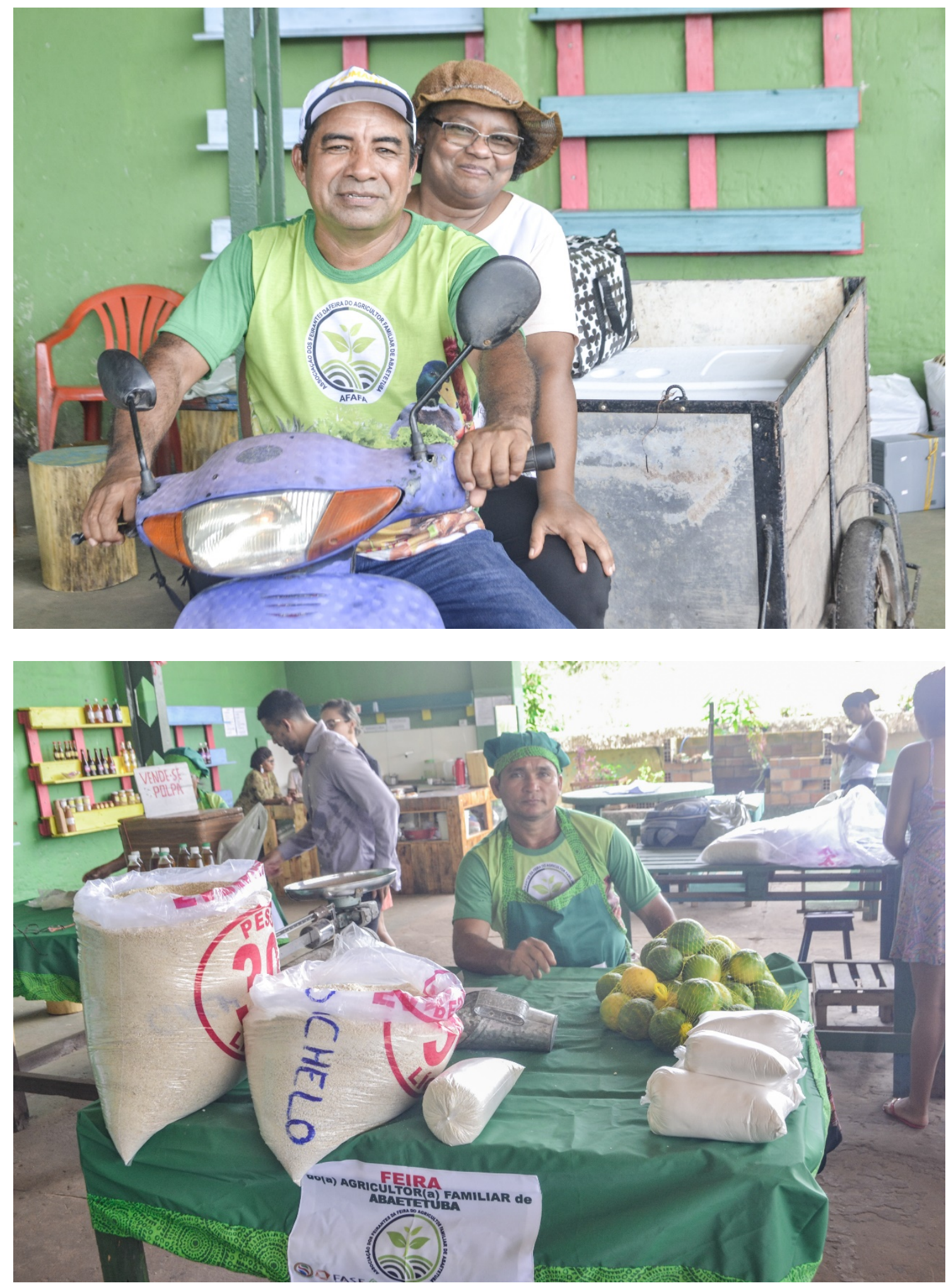